\title{
Direct-to-Consumer Television Advertising: Time to Turn Off the Tube?
}

\author{
Joseph S. Ross, MD, MHS ${ }^{7}$ and Richard L. Kravitz, MD, MSPH² \\ 'Section of General Internal Medicine and Robert Wood Johnson Foundation Clinical Scholars Program, Department of Medicine, Yale \\ University School of Medicine and Center for Outcomes Research and Evaluation, Yale-New Haven Hospital, New Haven, CT, USA; ${ }^{2}$ Division \\ of General Internal Medicine, University of California-Davis, Sacramento, CA, USA.
}

$\mathrm{J}$ Gen Intern Med 28(7):862-4

DOI: $10.1007 / \mathrm{s} 11606-013-2424-2$

(c) Society of General Internal Medicine 2013

$\mathrm{T}$ 1997 U.S. Food and Drug Administration (FDA) Modernization Act (FDAMA) relaxed regulation of direct-to-consumer (DTC) advertising of pharmaceutical and other medical products, allowing marketers to create advertisements that name branded products and conditions treated, along with a "major statement" of the most important product risks and reference to additional sources of information (usually the manufacturers' websites). ${ }^{1}$ Previously, marketers were required to include a "brief summary" of side effects, contraindications, and effectiveness ${ }^{1}$ that was generally too long for television advertisements, essentially limiting their use. Since FDAMA was enacted, DTC pharmaceutical marketing rose from $\$ 700$ million in advertisement spending in 1996 to $\$ 5.4$ billion in 2006 (a nearly $800 \%$ increase); more recent estimates from 2010 suggest spending of $\$ 4.3$ billion. $^{2}$

Over these past 15 years, advocates and opponents of DTC pharmaceutical advertising have tirelessly debated the merits (and demerits) of these marketing programs. Advocates typically argue that DTC advertising functions as public health service announcements, informing patients, and strengthens physician-patient relationships, citing surveys that suggest that advertisements increase the likelihood that patients will visit physicians to discuss an untreated medical illness, particularly illnesses that are under-recognized or stigmatized, and that such patients, prompted by the advertisements, will be more likely to be adherent to therapy 6 months later. ${ }^{3}$

In contrast, opponents argue that DTC advertising is nothing more than marketing - an attempt to get someone to buy something, with minimal potential public health benefit (even taking into account raised disease awareness) and serious risk, including patient anxiety, unnecessary treatment, excess prescription drug spending and perhaps even unnecessary physician visits. ${ }^{4,5}$ Unfortunately, there have been few objective examinations of the potential benefits and risks of DTC advertising, diminishing any possibility of

Published online March 29, 2013 reassurance or any imperative to modify its use as a marketing strategy.

At the level of the interaction between patients and physicians, a randomized trial assigning standardized patients to different roles demonstrated that brand-specific anti-depressant requests, or even requests for medications more broadly, had a profound effect on physician prescribing in major depression and adjustment disorder. In comparison to when standardized patients did not make any requests, family physicians and general internists were much more likely to prescribe a medication to standardized patients making advertisement-stimulated requests, and were far more likely to prescribe the requested brand to those making brand-specific medication requests. ${ }^{6}$

Studies that have examined the issue at the population level have similarly found DTC advertising to be associated with greater prescribing. For example, one study suggested that DTC antidepressant advertising was associated with an increase in the number of people diagnosed with depression who initiated medication therapy. ${ }^{7}$ However, a key limitation of previous research on this subject has been the inability to differentiate DTC advertising's effect on averting underuse (through enhanced recognition of symptoms and more prompt diagnosis) and promoting overuse (by encouraging pharmaceutical therapy for patients with sub-threshold conditions or mild symptoms, in whom the risks of pharmacotherapy might exceed the benefits).

In this issue of the Journal of General Internal Medicine, Niederdeppe et al. are able to examine this issue. Using data from the Simmons National Consumer Survey and Kantar/ TNS Media Intelligence, the investigators examined the relationship between estimated exposure to DTC television advertising for 'statin' medications and both diagnosis with high cholesterol and statin use. ${ }^{8}$ Taking into account advertisement frequency and television viewing patterns, exposure to statin advertisements was associated with a nearly $20 \%$ increased odds of being diagnosed with high cholesterol and a nearly $22 \%$ increased odds of statin use, driven almost exclusively by adults at low risk for future cardiac events. Exposure to statin advertisements had no impact on the likelihood of diagnosis with high choles- 
terol or statin use among adults at high risk for future cardiac events.

These provocative findings should be interpreted with some caution. The measure of DTC television advertising exposure was indirect. Moreover, the diagnosis of high cholesterol was by patient report and was not confirmed using high or low density lipoprotein values. Nevertheless, the consistency of the findings, the doseresponse relationship, and the specificity of the exposure-prescribing relationship (exposure to DTC advertising for antidepressants was not associated with statin use)-all point to an association that should, at the least, be taken seriously.

These findings add to the weight of evidence that DTC advertising likely promotes unnecessary treatment, which in turn would lead to excessive prescription drug spending. By now, we are all familiar with the ubiquitous pharmaceutical advertisements that attract our attention during commercial breaks interspersed within our television programming. But now, we can be more certain that this advertising is, in fact, marketing not public health service announcements - at that, at least in some circumstances, it is effectively getting someone to buy something that they do not need.

So what can or should be done? Because of First Amendment protections on commercial speech, a ban on DTC advertising in the United States is unlikely. ${ }^{9}$ Moreover, given the effectiveness of DTC advertising, we likewise cannot expect pharmaceutical and other medical product companies to voluntary discontinue DTC advertising. It seems equally futile to pursue a counter-education campaign, given the cost of television advertising and the growth in targeted internet spending, which has the potential to be an even more effective marketing strategy given the ability to target consumers and tailor advertisements accordingly. And for better or for worse, no one is turning off their tubes; television viewing in the United States only continues to grow. ${ }^{10}$

The most appropriate path forward, which is intended to maximize potential public benefit through the promotion of safe, evidence-based therapy in the context of known (and expected) industry spending on DTC advertising, is an approach based on a proposal previously made by one of us (RLK). ${ }^{5}$ Under the auspices of a government organization already responsible for publicly conveying clinically-important information, such as promoting disease awareness, pharmaceutical safety and effectiveness, or dissemination of clinical study findings (which includes, among several organizations, the Centers for Disease Control, the FDA, the Agency for Healthcare Research and Quality, or the National Institutes of Health), a public-private partnership would be created, led by an industry-funded, publicly administered consortium of experts from government, academia, and industry itself. The consortium would be charged with developing public service announcements and other educational materials emphasizing appropriate treatment solely for conditions which meet the following criteria: 1) the condition is associated with serious morbidity and mortality; 2) the condition is underdiagnosed and undertreated in the population; and (3) treatments are available for the condition that are effective and safe. Annual industry funding for this consortium would be mandated through legislation to be directly proportional to DTC advertising spending during the prior year. In this way, the consortium would promote the appropriate diagnosis and treatment of conditions for which effective therapies are available and are safe, averting population underuse through enhanced recognition of symptoms and more prompt diagnosis.

In summary, the benefits and harms of DTC advertising of prescription drugs have been fiercely debated for more than a decade. However, these arguments have been relatively uninformed by objective data. The article by Niederdeppe et al. lends credence to the charge that, at least in some clinical circumstances, exposure to DTC advertising promotes needless and possibly harmful prescribing. Their findings are unlikely to convince the Supreme Court that DTC advertising is something other than protected speech. But they should spur efforts to effectively regulate these ads so as to mitigate their most harmful effects.

Funding/Support and Role of the Sponsor: This article was not supported by any external grants or funds. Dr. Ross receives support from the National Institute on Aging (K08 AG032886) and the American Federation for Aging Research through the Paul B. Beeson Career Development Award Program, from the Centers of Medicare and Medicaid Services (CMS) within the Department of Health and Human Services to develop and maintain hospital performance measures that are used for public reporting; from Medtronic Inc. to develop methods to promote clinical trial data sharing, and from the Pew Charitable Trusts to examine pharmaceutical regulatory policy in the United States.

Conflict of Interest: Dr. Ross is a member of a scientific advisory board for FAIR Health, Inc.

Corresponding Author: Joseph S. Ross, MD, MHS; Section of General Internal Medicine, Yale University School of Medicine, P.O. Box 208093, New Haven, CT 06520, USA (e-mail:joseph.ross@yale.edu).

\section{REFERENCES}

1. U.S. Food and Drug Administration. Guidance for Industry: ConsumerDirected Broadcast Advertisements. Accessed March 5, 2013. Available at: http://www.fda.gov/downloads/Drugs/GuidanceCompliance RegulatoryInformation/Guidances/UCM070065.pdf

2. Bulik BS. Ad Spending: 15 Years of DTC, an Ad Age Insights White Paper. Accessed March 5, 2013. Available at: http://www.adage.com/ images/bin/pdf/WPpharmmarketing_revise.pdf

3. Holmer AF. Direct-to-consumer advertising-strengthening our health care system. N Engl J Med. 2002;346(7):526-8.

4. Wolfe SM. Direct-to-consumer advertising-education or emotion promotion? N Engl J Med. 2002;346(7):524-6. 
5. Kravitz RL, Bell RA. Direct-to-consumer advertising of prescription drugs: balancing benefits and risks, and a way forward. Clin Pharmacol Ther. 2007;82(4):360-2.

6. Kravitz RL, Epstein RM, Feldman MD, et al. Influence of patients requests for direct-to-consumer advertised antidepressants: a randomized controlled trial. JAMA: J Am Med Assoc. 2005;293(16):1995-2002.

7. Donohue JM, Berndt ER, Rosenthal M, Epstein AM, Frank RG. Effects of pharmaceutical promotion on adherence to the treatment guidelines for depression. Med Care. 2004;42(12):1176-85.
8. Niederdeppe J, Byrne S, Avery RJ, Cantor J. Direct-To-Consumer Television Advertising Exposure, Diagnosis with High Cholesterol, and Statin Use. Journal of General Internal Medicine. 2013; doi:10.1007/ s11606-013-2379-3.

9. Shuchman M. Drug risks and free speech-can Congress ban consumer drug ads? N Engl J Med. 2007;356(22):2236-9.

10. The Nielsen Company. State of the Media Trends in TV Viewing-2011 TV Upfronts. Accessed March 5, 2013. Available at: www.nielsen.com/.../ State-of-the-Media-2011-TV-Upfronts.pdf 